\title{
Pachydermoperiostosis (primary hypertrophic osteoarthropathy): report of a case with evidence of endothelial and connective tissue involvement
}

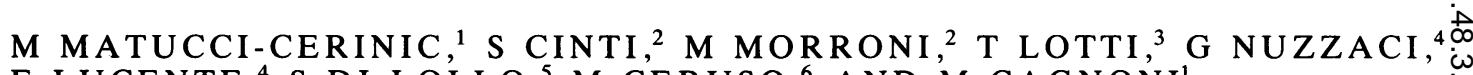
E LUCENTE, ${ }^{4}$ S DI LOLLO, ${ }^{5}$ M CERUSO, ${ }^{6}$ AND M CAGNONI

From the ${ }^{1}$ Istituto di Clinica Medica IV, Patologia Medica I, Università di Firenze; the ${ }^{2}$ Istituto do̊ Morfologia Umana Normale, Università di Ancona; the ${ }^{3}$ Istituto di Clinica Dermosifilopatica, Università di Firenze; the ${ }^{4}$ Istituto di Clinica Medica I, Cattedra di Angiologia, Università di Firenze; the ${ }^{5}$ Istituto d $\overrightarrow{\vec{b}_{3}}$ Anatomia Patologica, Università di Firenze; and ${ }^{6} \mathrm{UO}$ di chirurgia della mano e microchirurgia ricostruttiva, Centro Traumatologico Ortopedico, Florence, Italy

SUMMARY A case of pachydermoperiostosis characterised by the presence of finger clubbing periostosis, sweating of hands and feet is described. Modifications of capillaroscopic pattern and of arteriovenous anastomoses are reported. The periungual border and finger tip tissue showecक diffuse endothelial hyperplasia, hyalinosis, and sclerosis with packing of collagen fibres. Electrorit microscopy showed hypertrophic and activated endothelia (numerous and hypertrophic Golg 2 complexes, several Weibel-Palade bodies, vesicles of micropinocytosis, and glycogen particles) $\overrightarrow{\overrightarrow{0}}$ the basal membrane thickened and reduplicated, perivasal infiltrate in superficial dermaß reticulation and segmentary reduplication of basal membrane in arteriovenous shunt. In the perineural connective tissue numerous Luse bodies (long spacing collagen) were evident. The data indicate that in the early phase of pachydermoperiostosis morphological endothelial and collagen fibre abnormalities are present, though there is a normal peripheral blood flow.

Key words: endothelial activation; fibrous long spacing collagen.

Pachydermoperiostosis is a well recognised nondominant autosomal disease ${ }^{12}$ characterised by a wide spectrum of symptoms (pachydermia, finger clubbing, bone periostosis, seborrhoea, arthritis or arthralgia, and acro-osteolysis). ${ }^{3}$

Two forms of hypertrophic osteoarthropathy are known: a primary form-or pachydermoperiostosis of unknown origin-and a secondary form-or hypertrophic osteoarthropathy related to neoplastic or chronic diseases, or both, involving lung, liver, or heart.

This paper describes modifications of vessels and connective tissue in pachydermoperiostosis.

Accepted for publication 27 June 1988.

Correspondence to Dr M Matucci-Cerinic, via P Thouar 18, 50122 Florence, Italy.

\section{Case report}

A 19 year old male Caucasian patient with a historyo of finger clubbing, pachydermia, and excessiven sweating of the hands and feet was studied in 1983 These symptoms had started at the end of 1981 when $\omega$ he was 17. The patient was the first of two children and of the family members still alive, only the father had mild finger clubbing without any other symptoms or sign.

Physical examination showed finger clubbing of severe grade (hyponychial angle greater than $208^{\circ}$ ) pachydermia (more evident in the face), and gener $\frac{?}{\mathrm{P}}$ alised hyperhidrosis. The digital phalanges were violet-red and tender. The palms and soles showe profuse and continuous sweating. The wrists were 


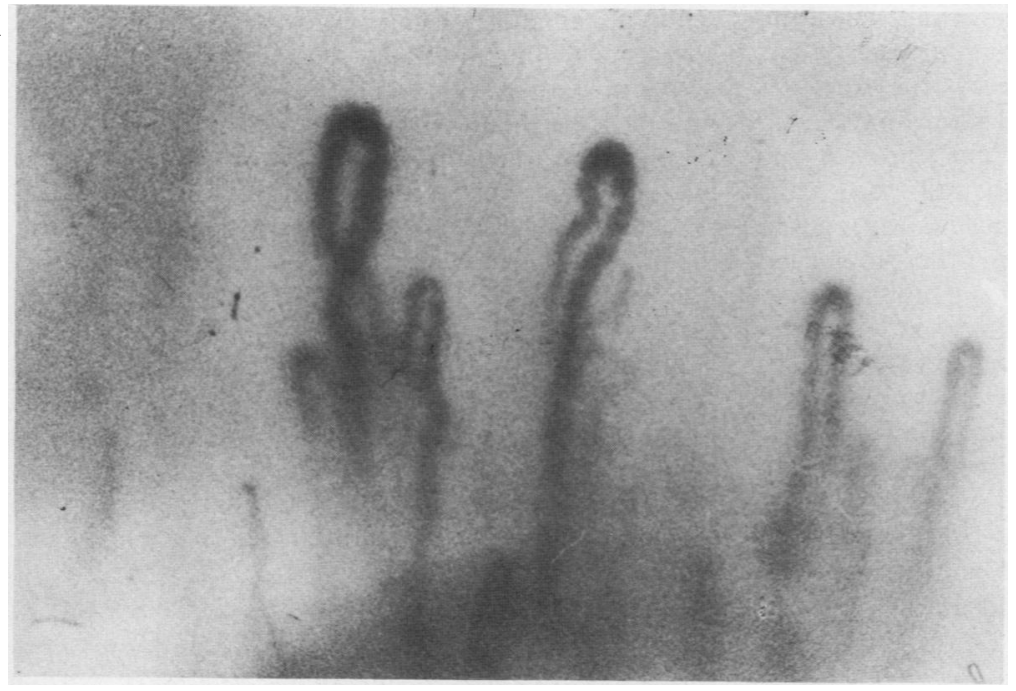

Fig. 1 Nail bed capillaroscopy: capillary loops appear irregular, serpiginous, and ectasic on the venular side in particular.

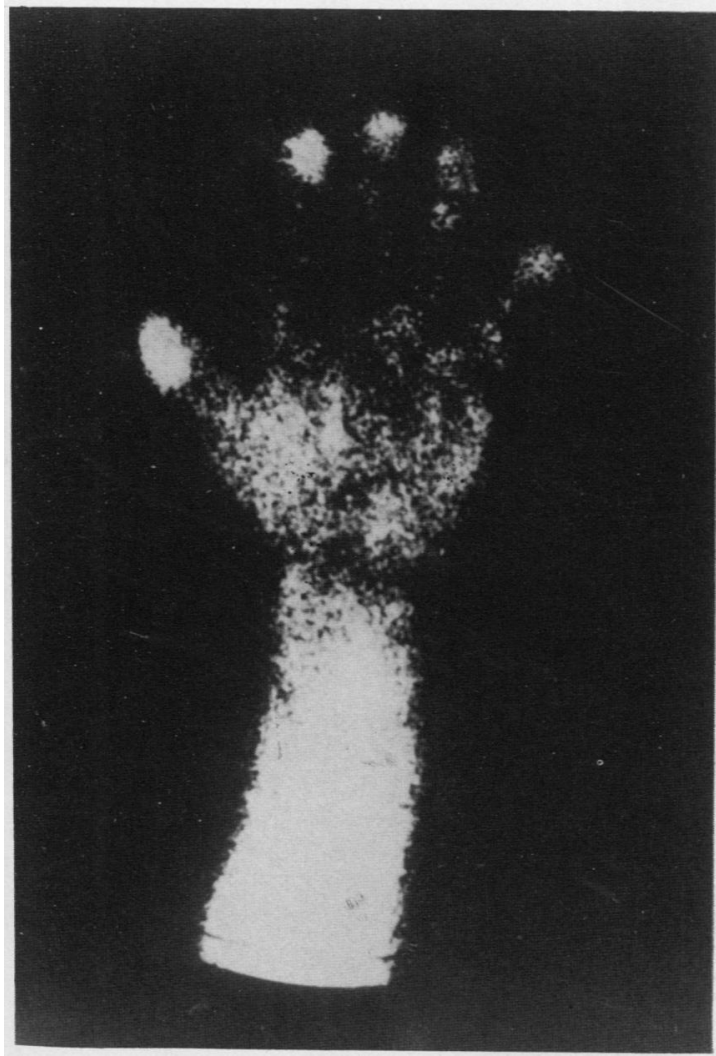

Fig. 2 Scintigraphy of the hands shows an intensive accumulation of microspheres in the finger tips.

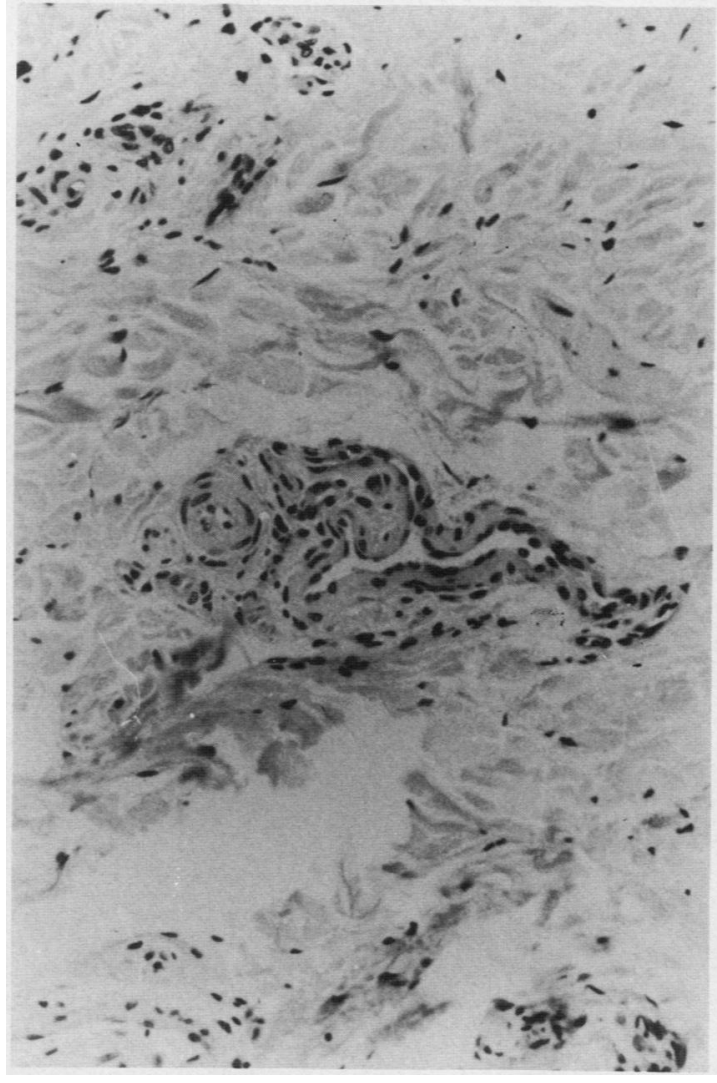

Fig. 3 Endothelial hyperplasia and sclerotic wall thickening with partial occlusion of the vascular lumen. (Haematoxylin and eosin.) 
enlarged, but the legs were not deformed. No joint inflammation or effusion was present. An $x$ ray examination showed slight periostosis of the diaphyses of the long bones (upper and lower limbs), but acro-osteolysis was not evident. The chest $x$ ray and routine haematological tests did not show any abnormalities. After informed consent the patient underwent the following studies: thermography, photoplethysmography and strain gauge plethysmography, a Doppler study, capillaroscopy, scintography of the arteriovenous anastomoses, and a bone scintiscan ( ${ }^{99 \mathrm{~m}} \mathrm{Tc}$ methylene diphosphonate). Arteriography was refused. As the patient complained of paraesthetic hand discomfort surgical reduction of the distal phalanges was carried out. Biopsy specimens of the finger tips, periungual tissue, and dorsum of the hand were taken and studied by light and electron microscopy.

\section{Special studies}

Thermography did not show any signs of hyperthermia of hands and feet. Photoplethysmography and strain gauge plethysmography showed respectively $a^{\frac{5}{}}$ normal wave and a regular digital flow in all fingers $\stackrel{\vec{s}}{\vec{s}}$ at room temperature and with cold $\left(10^{\circ} \mathrm{C}\right.$ for ones minute) and heat $\left(40^{\circ} \mathrm{C}\right.$ for five minutes) testing 을 Doppler examination of the arteries of the uppex and lower limbs did not show any significan $\square$ changes. Nail bed capillaroscopy showed $(a)$ thin tortuous, and irregular capillaries with morphological heterogeneity of the loops and the presence o $\vec{p}$ atypical elements ('scalloped loops'); (b) new $\vec{L}$ capillary formation (thin calibre tortuous loops); ( $c$ W irregular distribution of loops along the periunguaw border (presence of three to four capillaries in of single papilla); and (d) sporadic ectasic loops witlpo homogeneous dilatation on the venular tract. Now flow abnormalities were observed (Fig. 1).

The arteriovenous anastomoses, measured by ab indirect method (injection into the brachial artery of $0.5 \mathrm{ml} \mathrm{37-111} \mathrm{kBq}{ }^{99 \mathrm{~m}} \mathrm{Tc}$ labelled human albumin microspheres of $20 / 40 \mathrm{~nm}$ diameter), were normad when compared with those of matched controls. $\frac{\Phi}{-}$ Scintigraphs carried out at $10^{\circ} \mathrm{C}$ showed an abnormat accumulation of microspheres in the finger tips of

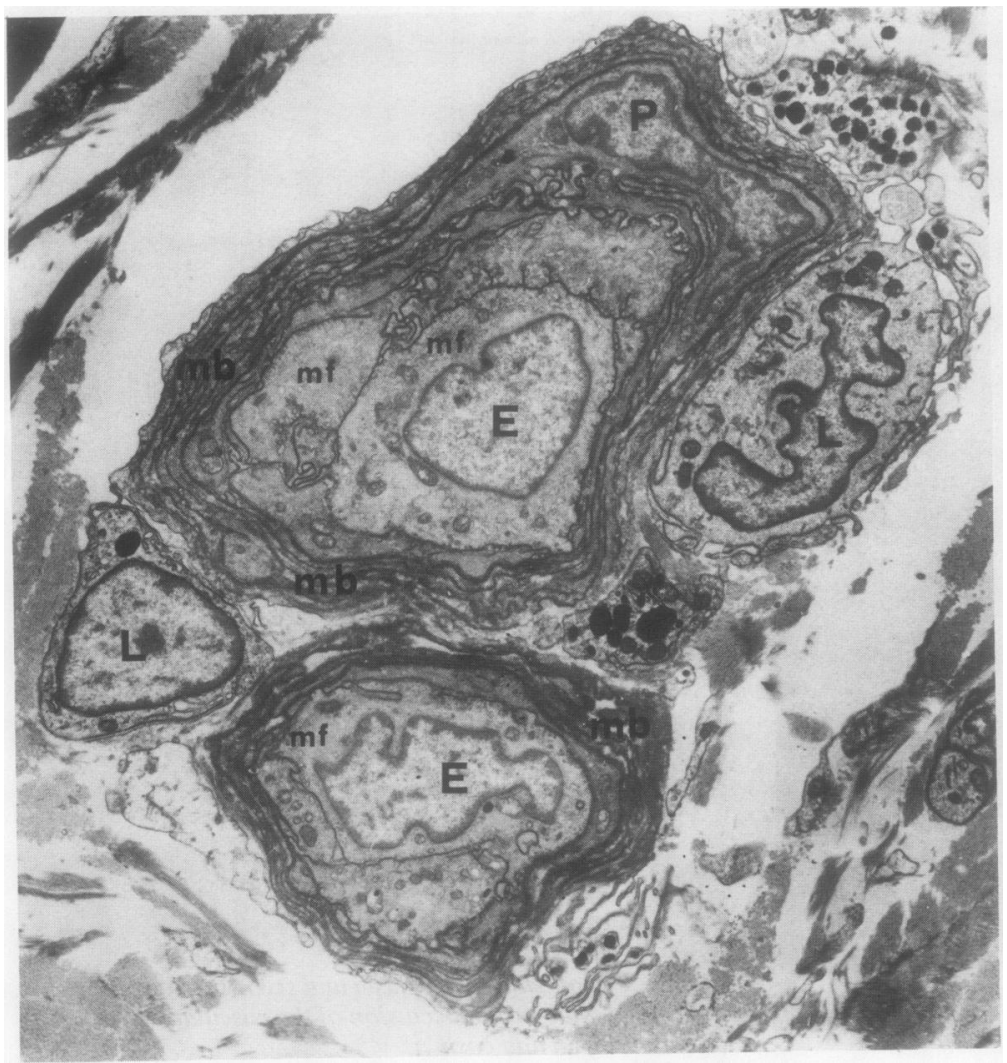

Fig. 4 Capillaries of the superficial dermis, in which a thickened, reduplicated basal membrane (mb), hypertrophic endothelial cells $(E)$ rich in microfilaments ( $m f$ ) and pseudo-occlusion of the lumen with pericapillary lymphocytic infiltrate (L) may be observed. $P=$ pericyte. 
both hands (Fig. 2). A ${ }^{99 m}$ Tc methylene diphosphonate bone scintiscan showed a slight pericortical concentration of the radionuclide along tibial and fibular, ulnar, and radial diaphyses.

Light microscopy examination of specimens from the finger tip and periungual zone (lesional skin) showed diffuse endothelial hyperplasia, more evident in the capillaries (Fig. 3), with partial occlusion of the vascular lumen. Capillary enlargement in the deep and interpapillary dermis was occasionally observed. An abundant pericapillary lymphohistiocytic infiltrate was always present. Hyalinosis and sclerosis, with thickening and packing of collagen fibres, were present in the connective tissue. The epidermis was acanthotic with a normal granular layer and thickening of the basal membrane. In the dermis the collagen bundles appeared to lose their outlines and fuse together. Sebaceous and eccrine glands appeared hypertrophic. ${ }^{3}$

Electron microscopy demonstrated the presence of capillaries in the superficial dermis that were in some places ectasic and in others characterised by hypertrophic and activated endothelia, which brought about pseudo-occlusion of the lumen (Fig. 4). Endothelial activation was characterised by a rich granular pattern with numerous and hypertrophic Golgi complexes, abundant microfilaments, numerous Weibel-Palade bodies, vesicles of micropinocytosis, and glycogen particles (Fig. 5). The basal membrane of the capillaries was thickened and reduplicated (Fig. 4). The arteriovenous anastomoses showed a reticulation and a segmentary reduplication of the basal membrane with signs of endothelial activation (Fig. 6). Perivascular infiltrate was present in the superficial derma (Fig. 4).

In the perineural connective tissue, close to the arteriovenous anastomoses, numerous Luse bodies (fibrous long spacing collagen) ${ }^{5}$ were observed (Fig. 7). The dermoepidermal basal lamina was normal.

The cutaneous biopsy specimen taken from apparently uninvolved hand dorsum showed qualitatively similar but less marked alterations than those detected in the finger tip and periungual zone, both with electron and light microscopy.

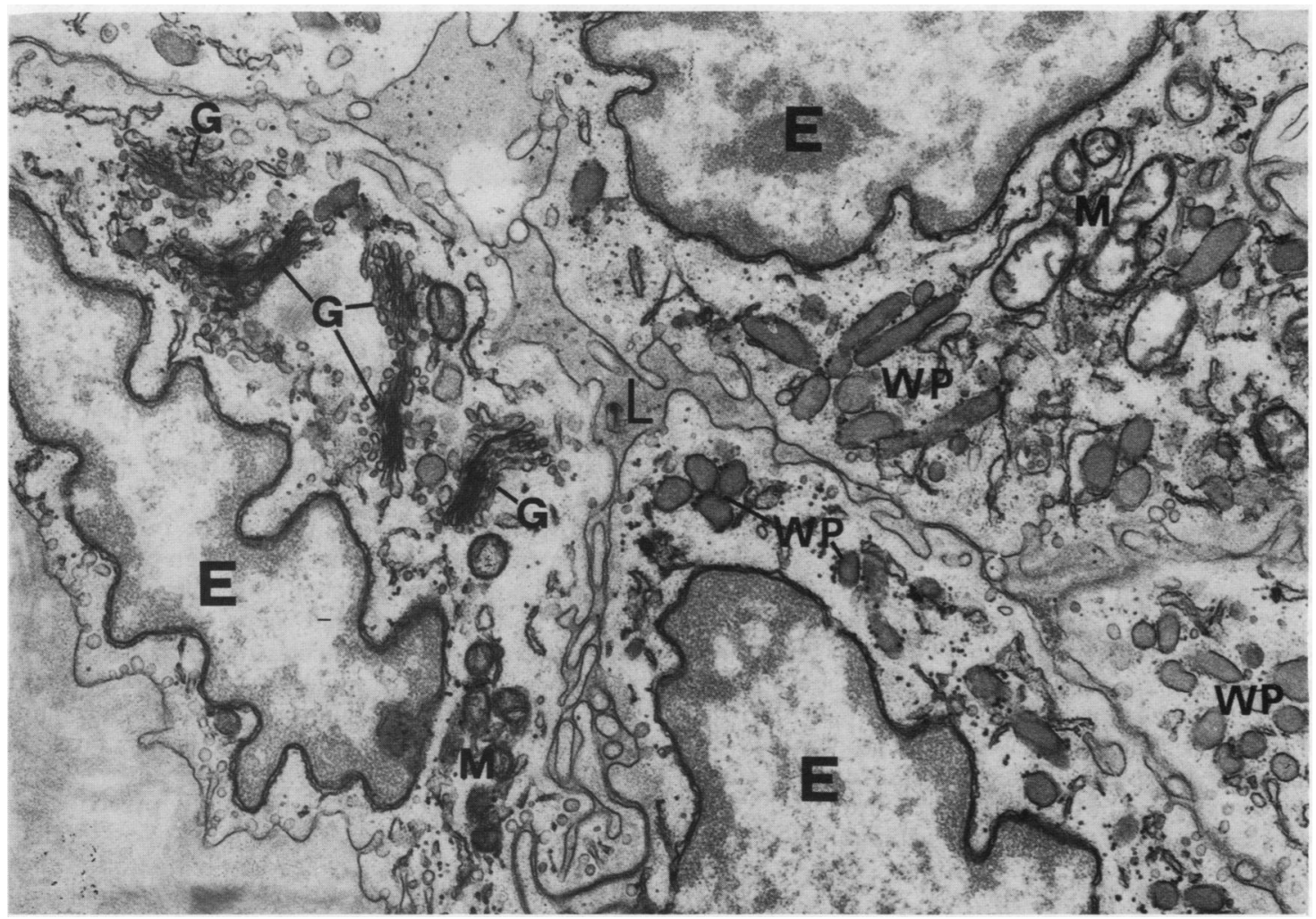

Fig. 5 Endothelial cells (E) of dermal capillaries. The presence of Weibel-Palade bodies (WP) may be noted. This is a sign of activation. $G=$ Golgi complexes; $M=$ mitochondria; $L=$ capillary lumen. 


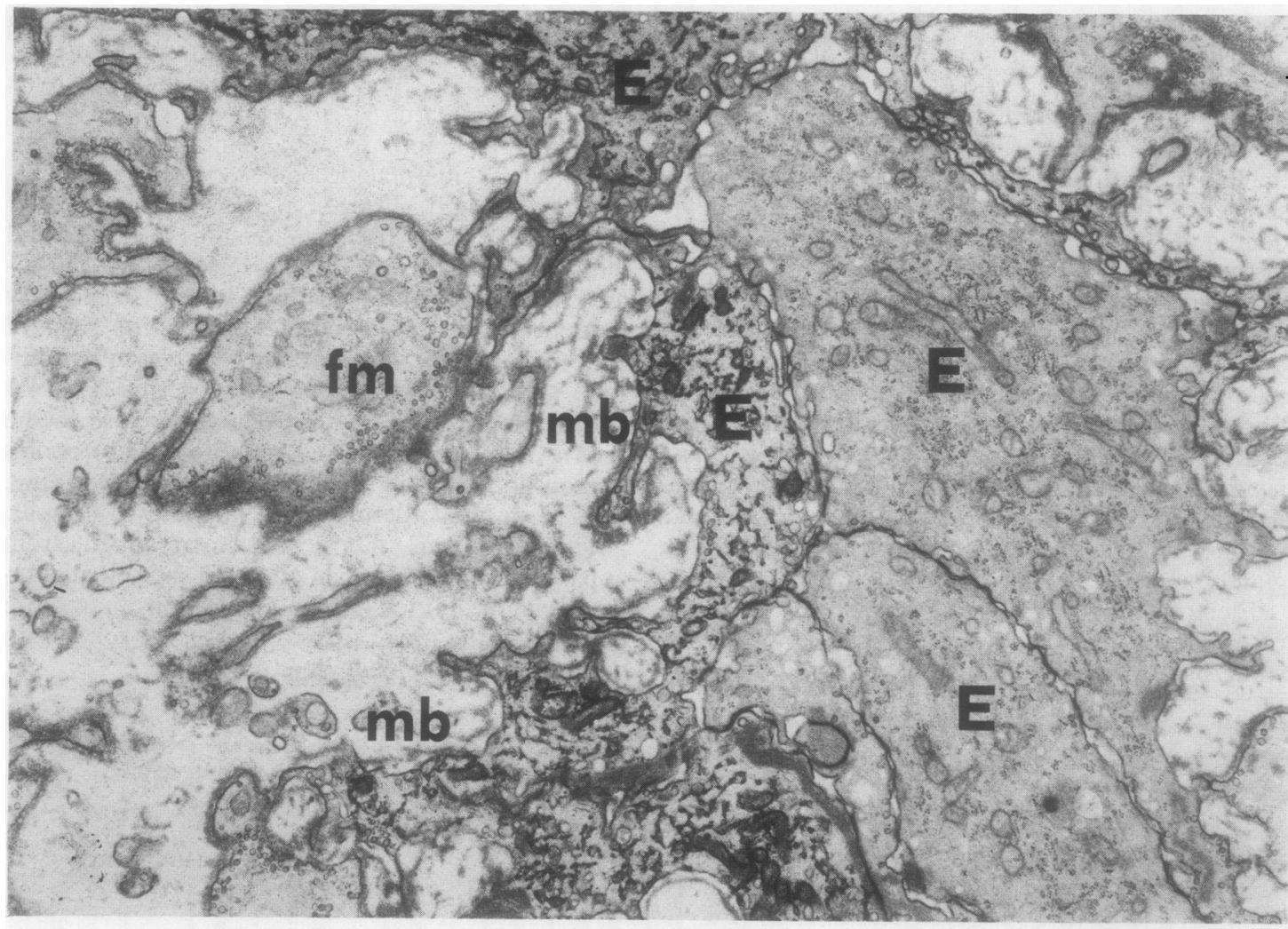

Fig. 6 Arteriovenous anastomoses. The reduplication and the reticulation of the basal membrane (mb) is visible. $E=$ endothelial cells; $f m=$ smooth myocell.

\section{Discussion}

The origin of pachydermoperiostosis is still unknown. In the last 20 years attention has been focused, with contradictory results, on the microvascular aspects of the disease. Some authors showed capillaroscopic abnormalities, ${ }^{67}$ segmental arterial abnormalities with obstructive phenomena, ${ }^{27}$ and increased venular fibrinolytic activity in the skin. ${ }^{8}$ Others detected an increased blood flow through the arteriovenous anastomoses and rapid filling of veins. ${ }^{9}$ Two authors described pachydermoperiostosis as having a normal blood flow. ${ }^{10}{ }^{11}$ In the present case, which may be regarded as being in the early phase of the disease because of the recent onset, we found a normal peripheral blood flow judged by thermographic, plethysmographic, capillaroscopic, and Doppler studies.

Capillaroscopy showed irregular capillaries with ectasic venular loops; these abnormalities, together with the pathological alterations observed in this phase of the disease, indicate a microangiopathy and a tendency towards vascular neoformation. These alterations and the described endothelial activation 3 may be induced by an unknown factor, ${ }^{12}$ as alreadyo suggested for systemic sclerosis. ${ }^{13}$

A division of the clinical course of pachyder- -0 moperiostosis into two phases has been proposed ${ }^{6} 7$. the first phase, early active with increased blood $\sigma$ flow, and the second, late inactive with reduced N blood flow. It is difficult to classify our patient in the N first phase of pachydermoperiostosis as we found $\sigma$ normal peripheral blood flow with plethysmography, Doppler studies, and capillaroscopy. It is possible? that our case is in a phase characterised by pathological alterations that immediately precede the phase with increased blood flow. Scintigraphy showed a normal patency at room temperature, but $\Phi^{+}$ the cold test at $10^{\circ} \mathrm{C}$ showed an abnormality in $\frac{\text { }}{\mathbb{Q}}$ arteriovenous anastomoses functioning similar to $\circ$ that in Raynaud's phenomenon. ${ }^{4}$ It may be that this functional alteration is related to the cellular modifi-o 


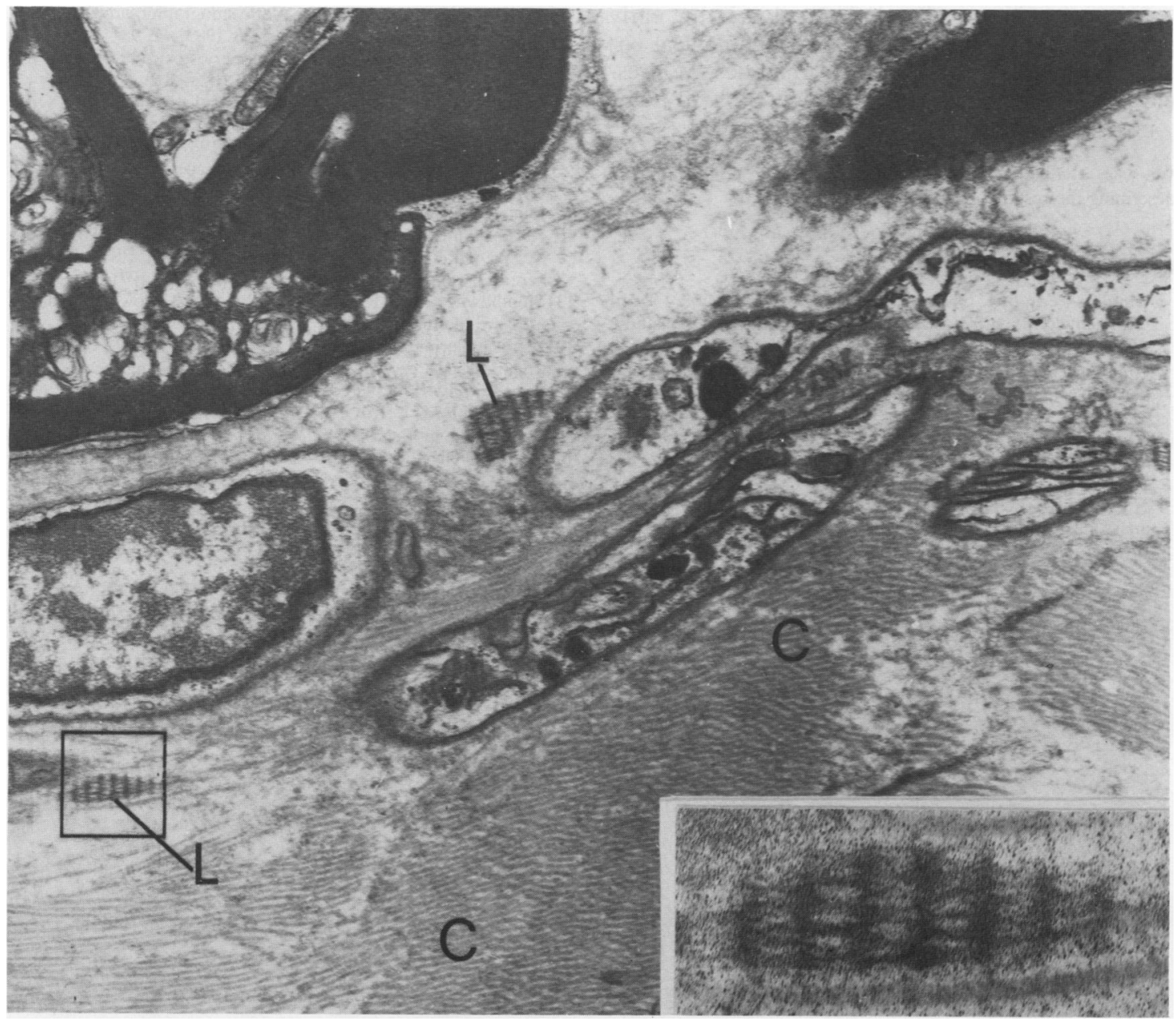

Fig. 7 Two Luse bodies $(L)$, immersed in collagen fibres $(C)$, are present in the perineural connective tissue. In the insert one Luse body is greatly magnified.

cations observed in the dermal microvessels. In fact the ultrastructural investigation showed that $(a)$ endothelial cells, whether of capillaries or of arteriovenous anastomoses, are activated. This could account for the partial occlusion of the capillary lumen; (b) numerous Weibel-Palade bodies are present; $(c)$ there is thickening and diffuse reduplication of the basal membrane of the capillaries, even those that are ectasic, as well as reticulation and segmentary reduplication of the basal membrane of the arteriovenous anastomoses; $(d)$ there is always the presence of a dense perivascular lymphocytic infiltrate.
These ultrastructural findings observed in the dermal microvessels are frequently found in the course of microangiopathy of different origin-for example, scleroderma. ${ }^{14}$ In addition, in our case numerous Luse bodies were found in dermal perineural connective tissue. These correspond to collagen fibrils with a periodicity that differs from that of normal collagen. ${ }^{515}$ They are not normally present in the healthy dermis, but they may be found in sclerodermic skin and in many other diseases. ${ }^{15}$ An increase in tissue concentration of glycosaminoglycans seems related to the presence of Luse bodies. ${ }^{16}$ 
In conclusion, our data indicate that in the early phase of pachydermoperiostosis morphological endothelial and collagen fibre abnormalities are present, while there is a normal peripheral blood flow.

We wish to thank Dr W Grassi for his helpful contribution in describing the results of capillaroscopy.

\section{References}

1 Matucci-Cerinic M, Giovannucci M L, Bussani C, Jajic I, Lotti T. Pachydermoperiostosis: a clinical and cytogenetic study. Haematologica (in press)

2 Rimoin D L. Pachydermoperiostosis (idiopathic clubbing and periostosis). Genetic and physiologic considerations. $N$ Engl J Med 1965; 272: 924-31.

3 Vogl A, Goldfischer S. Pachydermoperiostosis: primary or idiopathic hypertrophic osteoarthropathy. Am J Med 1962; 33: 166-87.

4 Nuzzaci G, Pesciullesi E, Lucarelli F, et al. Arteriolo-venular anastomoses function and Raynaud's phenomenon. Angiology (in press).

5 Luse S A, Zopf D, Cox J W. An electron microscopic study of in vitro and in vivo long spacing collagen. Anat Rec 1963; 145: 254-8.

6 Fam A G, Chin-Sang H, Ramsay C A. Pachydermoperiostosis: scintigraphic, thermographic, plethysmographic and capillaroscopic observations. Ann Rheum Dis 1983; 42: 98-102.

7 Kerber R E, Vogl A. Pachydermoperiostosis. Peripheral and circulatory studies. Arch Intern Med 1973; 132: 245-8.

8 Matucci-Cerinic M, Lotti T, Jajic I, di Lollo S, Brunetti L, Orlic D. Cutaneous fibrinolytic activity in primary hypertrophic osteoarthropathy. Scand J Rheumatol 1987; 16: 205-12.

9 Jajic I, Pecina M, Krstulovic B, Kovacevic D, Spaventi S Primary hypertrophic osteoarthropathy and changes in the्छ joints. Scand J Rheumatol 1980; 9: 89-96.

10 Racoceanu S N, Mendlowitz M, Suck A F, Wolf R L, Naftch N E. Digital capillary blood flow in clubbing. ${ }^{85} \mathrm{Kr}$ studies in hereditary and acquired cases. Ann Intern Med 1971; 75: 933-5.

11 Mendlowitz M. Measurements of blood flow and bloo pressure in clubbed fingers. J Clin Invest 1941; 20: 113-7.

12 Matucci-Cerinic M, Fattorini L, Gerini G, et al. Colchicine

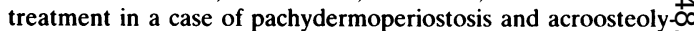
sis. Rheumatol Int 1988; 8: 185-8.

13 Campbell P M, LeRoy E C. Pathogenesis of systemis sclerosis: N a vascular hypothesis. Semin Arthritis Rheum 1975; 4: 351-68.0

14 Cinti S, Sbarbati A, Grassi W. L'ultrastruttura del microvaso ino alcune malattie di interesse reumatologico. Clin Ter 1984; 108: 27-41.

15 Ghadially F N. Fibrous long spacing collagen. In: Ghadially F $\mathrm{N}$, ed. Ultrastructural pathology of the cell matrix. London: Butterworth, 1982: 894-981.

16 Yardley J H, Brown G D. Fibroblasts in tissue culture. Use of colloidal iron for ultrastructural localization of acid mucopoly saccharides. Lab Invest 1965; 14: 501-4. 